\title{
Progressive Fracture of Fiber Composite Thin Shell Structures Under Internal Pressure and Axial Loads
}

Pascal K. Gotsis and Christos C. Chamis

Lewis Research Center

Cleveland, Ohio

Levon Minnetyan

Clarkson University

Potsdam, New York

September 1996

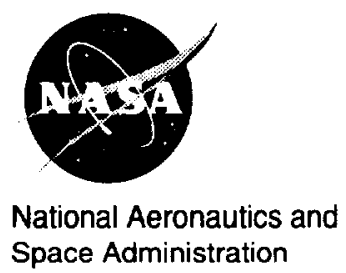


Trade names or manufacturers' names are used in this report for identification only. This usage does not constitute an official endorsement, either expressed or implied, by the National Aeronautics and Space Administration. 


\title{
PROGRESSIVE FRACTURE OF FIBER COMPOSITE THIN SHELL STRUCTURES UNDER INTERNAL PRESSURE AND AXIAL LOADS
}

\author{
Pascal K. Gotsis and Christos C. Chamis \\ National Aeronautics and Space Administration \\ Lewis Research Center, Cleveland, Ohio 44135 \\ and \\ Levon Minnetyan \\ Clarkson University \\ Potsdam, New York 13699-5710
}

SUMMARY

Graphite/epoxy composite thin shell structures were simulated to investigate damage and fracture progression due to internal pressure and axial loading. Defective and defect-free structures (thin cylinders) were examined. The three laminates examined had fiber orientations of $[90 / 0 / \pm \theta]_{\mathrm{s}}$, where $\theta$ is $45^{\circ}, 60^{\circ}$, and $75^{\circ}$. CODSTRAN, an integrated computer code that scales up constituent level properties to the structural level and accounts for all possible failure modes, was used to simulate composite degradation under loading. Damage initiation, growth, accumulation, and propagation to fracture were included in the simulation. Burst pressures for defective and defect-free shells were compared to evaluate damage tolerance.

The results showed that damage initiation began with matrix failure whereas damage and/or fracture progression occurred as a result of additional matrix failure and fiber fracture. In both thin cylinder cases examined (defective and defect-free), the optimum layup configuration was $[90 / 0 / \pm 60]_{\mathrm{s}}$ because it had the best damage tolerance with respect to the burst pressure.

\section{INTRODUCTION}

Graphite/epoxy composite shell structures are used in various structural components such as aircraft fuselages, jet engine cowls, pressure vessels, and rocket motor cases. In these applications, it is important to achieve low weight, high strength, stiffness, and safety when composite shells are required to withstand significant internal pressures. This report discusses thin cylindrical shells subjected to internal pressure. Damage initiation, growth, accumulation, and propagation to fracture were simulated for three cases.

For a rational design, it is necessary to quantify the defect and damage tolerance of a candidate structure. Assessing this tolerance requires the capability to simulate the progressive damage and fracture characteristics of composite structures under loading. Critical components of a structure must remain safe but be able to function under loading after experiencing some damage. Damage may be caused by an accident, a defect, or an unexpected overloading. A structure's tolerance to damage is quantified by the residual strength (i.e., the additional loadcarrying ability after damage).

Another design consideration is the multiplicity of options such as fiber orientation patterns and constituent material combinations, choices that result in a great number of parameters that may be varied for an optimal design.

Design considerations with regard to the progressive fracture of fiber composite structures require a priori evaluation of damage initiation and fracture propagation mechanisms under expected loading and service environments. Concerns for the safety and survivability of critical components require that the structural fracture resistance under loading be quantified. The present approach bypasses traditional fracture mechanics to provide an alternative evaluation method, conveying to the design engineer a detailed description of damage initiation, growth, accumulation, and propagation that would occur in the ultimate fracture of a fiber composite structure. The results show in detail the damage progression sequence and structural fracture resistance during different degradation stages. 
The laminate configuration is a significant design parameter with regard to composite damage tolerance. In general, quasi-isotropic laminates have better damage tolerance (ref. 1). However, in many cases when there is no damage, a quasi-isotropic laminate may not be the most efficient with regard to structural strength and performance. A rational design process requires that the structural damage tolerance for a candidate design be quantified because damage initiation and progression characteristics are much more complex for laminated fiber composites than they are for homogenous materials. The structural fracture process of a laminated fiber composite depends on many parameters: laminate configuration, fiber volume ratio, constituent stiffness, strength, and hygrothermal properties and the fabrication process.

Recent developments in computational simulation have made it possible to evaluate progressive damage and fracture in composite structures by assessing the damage initiation and propagation loads. Taken into account are the influence of local defects or flaws, through-the-thickness cracks, and the effects of the fabrication process in terms of residual stresses. This report demonstrates that computational simulation, with the use of established material modeling and finite element modules, adequately tracks the damage growth and subsequent propagation to fracture of fiber composite pressurized shells. The present cylindrical shell simulations constitute an extension of the work reported in reference 1 in which the defect tolerance characteristics of cross-ply and quasi-isotropic laminates were investigated. The current study examines the effects of angle ply orientation on damage tolerance characteristics and structural fracture modes. The CODSTRAN (COmposite Durability STRuctural ANalysis) computer code was used to simulate the damage progression in a variety of composite structures: stiffened, adhesively bonded composite structures (ref. 2), adhesively bonded concentric composite cylinders (ref. 3), damage progression in bolted composite structures (ref. 4), progressive damage and fracture of adhesively bonded pipe joints (ref. 5), damage tolerance of composite pressurized shells (ref. 6), progressive fracture of fiber composite builtup structures (ref. 7), and progressive fracture of composite subjected to simulated Iosipescu shear testing (ref. 8).

This report describes the application of computational simulation to defect-free and damaged composite cylindrical shell specimens, taking into account damage initiation and/or propagation mechanisms. The purpose was to identify the salient material and structural parameters for a design with damage tolerance considerations.

\section{CODSTRAN METHODOLOGY}

CODSTRAN is an integrated computer code in which three modules are coupled: composite mechanics (ICAN), finite element analysis (MHOST), and damage progression modeling. ICAN (Integrated Composite Analyzer) is a composite mechanics computer code (ref. 9) that provides the constituent (fiber and matrix) material properties from an available data bank and computes the ply properties and the composite properties (effective properties) of the laminate in a hygrothermal environment. The code is based on the theory of the micromechanics of composites and the classical laminate theory. ICAN can compute ply stresses by using known stress resultants (force per laminate thickness, where force can be a bending, a twisting, or a concentrated load). In ICAN, two failure criteria were established for the detection of ply failures: (1) the maximum stress criterion in which individual ply failure modes are assessed by ICAN using failure criteria associated with the negative and positive limits of the six ply stress components in the material directions 1 to 3 (fig. 1):

$$
\begin{gathered}
S_{\ell 11 \mathrm{C}}<\sigma_{\ell 11}<S_{\ell 11 \mathrm{~T}} \\
\mathrm{~S}_{\ell 22 \mathrm{C}}<\sigma_{\ell 22}<\mathrm{S}_{\ell 22 \mathrm{~T}} \\
\mathrm{~S}_{\ell 33 \mathrm{C}}<\sigma_{\ell 33}<\mathrm{S}_{\ell 33 \mathrm{~T}} \\
\mathrm{~S}_{\ell 12(-)}<\sigma_{\ell 12}<\mathrm{S}_{\ell 12(+)} \\
\mathrm{S}_{\ell 23(-)}<\sigma_{\ell 23}<\mathrm{S}_{\ell 23(+)} \\
\mathrm{S}_{\ell 13(-)}<\sigma_{\ell 13}<\mathrm{S}_{\ell 13(+)}
\end{gathered}
$$


where $S_{\ell_{i j \alpha}}$ represents the ply stress limit (ply strength) in which the ij subscript indicates the stress component and the $\alpha$ subscript indicates the sense as tension and/or compression for normal stresses and as \pm for shear stress limits on the ply; $\sigma$ is the ply stress. The ICAN composite mechanics module computes $S_{\ell \text { ijo }}$ stress limits. (2) The modified distortion energy (MDE) criterion takes into account combined stresses and is expressed as

$$
\mathrm{F}=1-\left[\left(\frac{\sigma_{\ell 11 \alpha}}{S_{\ell 11 \alpha}}\right)^{2}+\left(\frac{\sigma_{\ell 22 \beta}}{S_{\ell 22 \beta}}\right)^{2}-K_{\ell 12} \frac{\sigma_{\ell 11 \alpha}}{S_{\ell 1 \alpha}} \frac{\sigma_{\ell 22 \beta}}{S_{\ell 22 \beta}}+\left(\frac{\sigma_{\ell 12 S}}{S_{\ell 12 S}}\right)^{2}\right]
$$

where $\alpha$ and $\beta$ indicate tensile or compressive stress, $S_{\ell 11 \alpha}$ is the ply longitudinal strength in tension or compression, $S_{\ell 22 \alpha}$ is the transverse strength in tension or compression, and

$$
\mathrm{K}_{\ell 12}=\frac{\left(1+4 v_{\ell 12}-v_{\ell 13}\right) \mathrm{E}_{\ell 22}+\left(1-v_{\ell 23}\right) \mathrm{E}_{\ell 11}}{\left[\mathrm{E}_{\ell 11} \mathrm{E}_{\ell 22}\left(2+v_{\ell 12}+v_{\ell 13}\right)\left(2+v_{\ell 21}+v_{\ell 23}\right)\right]^{1 / 2}}
$$

The type of failure is assessed by comparing the magnitudes of the squared terms in equation (7). Depending on the dominant term in the MDE failure criterion, fiber failure or matrix failure is assigned. If the first squared term in equation (7) that corresponds to ply longitudinal tensile or compressive failure is dominant, fiber failure is assigned. On the other hand, if one of the other squared terms corresponding to ply transverse tensile or compressive failure or to ply shear failure is dominant, matrix failure is assigned. For example, a laminate with configuration [90/0/ \pm 75$]_{\mathrm{s}}$ has ply stresses at the top ply $\left(90^{\circ}\right)$ and is shown in figure 2 . In ICAN, the described failure modes of the plies are failure due to fiber fracture in tension or in compression; damage due to matrix fracture in tension or in compression; and damage due to intralaminar shear fracture.

MHOST is a finite element computer code (ref. 10) used to solve structural analysis problems. The code can perform linear or nonlinear static and dynamic analyses. MHOST has a library containing a variety of elements, among which is the four-node shell element used for the present work. (This element is similar to element 75 in the MARC structural analysis finite element code.) By supplying the boundary conditions, the type of analysis desired, the applied loads, and the laminate properties (using ICAN), MHOST performs the structural analysis. In addition, MHOST provides the computed stress resultants to the ICAN code, which then computes the developed ply stresses for each ply and checks for ply failure.

The damage progression module monitors composite degradation for the entire structure and relies on ICAN for composite micromechanics, macromechanics, and laminate analysis. In this module, the overall evaluation of the composite structural durability is conducted.

The CODSTRAN simulation cycle is shown in figure 3. Proceeding clockwise along the left side, one sees the constituent material properties (fiber and matrix) provided by ICAN's data base, the ply properties computed from the micromechanics theory, and the laminate properties computed from the laminate theory. These properties in conjunction with the finite element mesh, the loads, and the boundary conditions are incorporated in MHOST, which performs the structural analysis and provides the computed stress resultants to ICAN (right side of the figure). ICAN uses the laminate theory to compute the ply stresses and to check for ply failure.

The nonlinear structural analysis in the MHOST code is performed in conjunction with an incremental load algorithm. The load is increased in small increments (equilibrium positions). In each position, a number of iterations (incremental damages) is performed (fig. 4) and the structure is checked for ply failure. If damage is detected, the model is automatically updated with a new finite element mesh and new laminate properties; then another finite element analysis is performed and the iterations continue until no further damage occurs (equilibrium position). At this point, the load is increased and the above procedure repeated until the final failure of the structure. The damage progression, fracture, and collapse of the structure are monitored during this procedure.

The CODSTRAN code is written in FORTRAN 77 computer language for UNIX operating systems at the NASA Lewis Research Center. 


\section{THIN SHELL STRUCTURES}

Damage and progressive fracture were investigated for internally pressurized graphite/epoxy laminated composite thin cylindrical shells. The shell structures consisted of eight $0.136-\mathrm{mm}(0.00535$-in.) plies resulting in a compos-

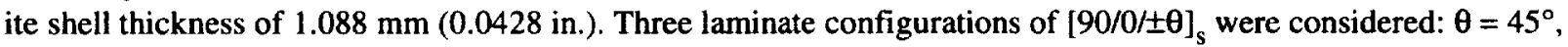
$60^{\circ}$, and $75^{\circ}$. The $90^{\circ}$ plies were in the hoop/circumferential direction of the shells and the $0^{\circ}$ plies were in the axial direction. Fiber orientations in the $\pm 45^{\circ}, \pm 60^{\circ}$, and $\pm 75^{\circ}$ (fig. 2) angle plies were given with reference to the axial directions. The geometry of the thin cylindrical shells was identical (inside diameter, $305 \mathrm{~mm}$ or $12.0 \mathrm{in}$.; length, $762 \mathrm{~mm}$ or $30 \mathrm{in}$.). The closed-end cylindrical pressure vessel was simulated by applying a uniformly distributed axial tension so that the generalized axial stresses in the shell wall were half those developed in the hoop direction (fig. 5). The composite shells were subjected to a monotonically increasing internal hydrostatic pressure until they burst. All laminate configurations, defect-free shells and those with through-the-thickness defects, were examined (fig. 5). Defects were modeled at a node located at the half-length of the shell. Each finite element model contained 544 nodes and 512 uniformly sized rectangular elements (fig. 6). Damage initiation, growth, fracture progression, and global structural fracture stages were investigated in each case. For both defective and defect-free shells, damage initiation was by matrix cracking due to transverse tensile stresses in the $0^{\circ}$ plies. For the defect-free shells, fiber fractures did not occur until just before the structural fracture pressure was reached. The fiber volume ratio was 60 percent and the void volume ratio was 2 percent of the total volume of the structure. The residual stresses due to the processing were taken into account. The cure temperature was $177^{\circ} \mathrm{C}\left(350^{\circ} \mathrm{F}\right)$; the pressurization/use temperature was $21^{\circ} \mathrm{C}\left(70^{\circ} \mathrm{F}\right)$, the moisture content was zero. The fiber and matrix properties were obtained from a CODSTRAN data bank of composite constituent material properties. The corresponding graphite fibers (AS-4) and epoxy matrix (high-modulus, high-strength (HMHS)) properties are given in tables I and II, respectively, and the AS-4/HMHS ply strength is given in table III. Computed results up to global fracture are presented for defect-free shells and those with through-the-thickness defects.

\section{Defect-Free Structures}

Simulations were conducted of defect-free pressurized shells that had three laminate configurations of $[90 / 0 / \pm \theta]_{\mathrm{S}}$ for which the ply layups were $\theta=45^{\circ}, 60^{\circ}$, and $75^{\circ}$. The results are summarized as follows:

The CODSTRAN simulation of $[90 / 0 / \pm 45]_{\mathrm{s}}$ indicated a damage initiation pressure of $0.799 \mathrm{MPa}$ (116 psi). Initial damage occurred near the closed ends of the shell and took the form of matrix cracking in selected plies. The damage progressed from cracking in the outermost $0^{\circ}$ ply to the $45^{\circ}$ ply immediately adjacent, to the innermost $0^{\circ} \mathrm{ply}$, and then to the $90^{\circ} \mathrm{ply}$ on the interior surface. After damage initiation, all plies gradually sustained matrix cracking as the pressure was increased to $0.837 \mathrm{MPa}(121 \mathrm{psi})$. After this stage, the pressure was significantly increased without activating additional damage modes. The cylindrical shell burst when the $90^{\circ}$ hoop plies experienced fiber fractures at a simulated burst pressure of $4.80 \mathrm{MPa}(0.696 \mathrm{ksi})$.

The CODSTRAN simulation of the $[90 / 0 / \pm 60]_{\mathrm{s}}$ configuration revealed that when the orientations of angle plies were changed to $\pm 60^{\circ}$, the damage initiation pressure was increased to $0.965 \mathrm{MPa}$ ( $140 \mathrm{psi}$ ). Similar to the case of $\pm 45^{\circ}$ angle plies, initial damage took the form of matrix cracking in selected plies. At first, the outermost $0^{\circ}$ ply (ply 2) developed matrix cracking due to ply transverse tensile stresses; the degradation of ply 2 was followed by that of ply 3 (the $60^{\circ}$ ply immediately adjacent to ply 2). Subsequently, ply 7 (the innermost $0^{\circ}$ ply) and ply 8 (the $90^{\circ}$ ply on the interior surface) developed matrix cracks. After damage initiation, all plies gradually sustained matrix cracking as the pressure remained virtually constant. After this initial damage growth stage, the pressure increased considerably without activating additional significant damage modes. The cylindrical shell burst when ply 1 (the outermost $90^{\circ}$ hoop ply) experienced fiber fractures that resulted in a rapid propagation of damage to structural fracture. The simulated burst pressure was $9.42 \mathrm{MPa}(1.366 \mathrm{ksi})$.

The computational simulation of the $[90 / 0 / \pm 75]_{\mathrm{s}}$ configuration indicated a damage initiation pressure of $1.062 \mathrm{MPa}(154 \mathrm{psi})$, which was the highest pressure of the three defect-free shells investigated. Damage initiation was by matrix cracking due to ply transverse tensile stresses in ply 2 (the outermost $0^{\circ}$ ply). Immediately after matrix cracking occurred in ply 2, plies 3, 7, and 8 experienced degradation. Failure modes were in-plane shear in ply 3 , transverse tensile in ply 7 , and transverse tensile and in-plane shear in ply 8 . Damage growth in the other plies occurred as the pressure was kept virtually constant. After the initial matrix degradation stage, the pressure was 
increased without activating additional damage modes. The cylindrical shell burst when ply 2 (the outermost $0^{\circ}$ axial ply) experienced fiber fractures that caused rapid damage propagation to the other plies and then structural fracture. The simulated burst pressure was $7.83 \mathrm{MPa}(1.136 \mathrm{ksi})$. It is noteworthy that structural fracture was initiated by the tensile failure of axial fibers in this case whereas in the previous two defect-free shells, structural fracture commenced by the fracturing of the hoop plies.

In general, overall structural damage may include individual ply damage and through-the-thickness fracture of the composite laminate. CODSTRAN is able to simulate varied and complex composite damage mechanisms by an evaluation of the individual ply failure modes and the associated degradation of laminate properties. The type of damage growth and the sequence of damage progression depend on the composite structure, loading, material properties, and hygrothermal conditions. A scalar damage variable, derived from the total volume of the composite material affected by the various damage mechanisms, is also evaluated as an indicator of the level of overall damage induced by loading. This scalar damage variable is useful for assessing the overall degradation of a given structure under a prescribed loading condition. The rate of increase in the overall damage during composite degradation may be used as a measure of the structural propensity for fracture. Figure 7 presents a comparison of the overall damage progression histories for the three defect-free cylindrical shells. Damage initiation pressures and progression patterns are similar. However, burst pressures are strongly influenced by the laminate configuration. The $[90 / 0 / \pm 60]_{s}$ defectfree laminate had the highest burst pressure. On the other hand, the $[90 / 0 / \pm 75]_{\mathrm{s}}$ defect-free laminate had the highest damage initiation pressure. The $[90 / 0 / \pm 45]_{\mathrm{S}}$ defect-free laminate had the lowest burst pressure as well as the lowest damage initiation pressure.

\section{Defective Structures}

Three additional simulations were conducted on shells that were modeled to have a through-the-thickness defect in the form of an existing 95-mm- (3.75-in.-) long thin axial slit superimposed on a 60-mm- (2.36-in.-) long circumferential slit at the half-length of the shell (fig. 6). Including a circumferential as well as an axial slit allowed selfsimilar crack propagation in the axial and circumferential directions. A summary of the computational simulation results for the through-the-thickness defective thin shells follows:

For the $[90 / 0 / \pm 45]_{\mathrm{S}}$ quasi-isotropic shell, damage initiation began by matrix cracking adjacent to the defect as soon as an initial pressure of $0.172 \mathrm{MPa}$ (25 psi) was applied. However, damage growth remained localized adjacent to the defect until a $0.745-\mathrm{MPa}$ (108-psi) pressure was reached. After damage initiation, all plies gradually sustained matrix cracking as the pressure was increased to $0.837 \mathrm{MPa}$ (121 psi). The damage accumulation stage (by matrix cracking) was similar to that of the defect-free shell. However, after the matrix cracking stage was completed, the damage propagation to ultimate fracture was much more rapid than that of the defect-free shell. Damage propagation by fiber fractures was concentrated near the defect. Through-the-thickness structural fracture progression occurred at $1.58 \mathrm{MPa}(0.230 \mathrm{ksi})$, causing the cylindrical shell to burst. For the $[90 / 0 / \pm 45]_{\mathrm{s}}$ laminate, the axial crack orientation was the more critical. Figure 8 shows the finite element model as the simulated defective shell burst.

Similar to the \pm 45 quasi-isotropic defective shell, damage initiation in the $[90 / 0 / \pm 60]_{\mathrm{S}}$ shell began by matrix cracking adjacent to the defect as soon as the initial pressure of $0.172 \mathrm{MPa}$ (25 psi) was applied. Initially, matrix failures at the circumferential slit tips commenced by transverse tensile failures in ply 8 , and matrix failures in the axial slit tips commenced by transverse tensile failures in ply 7 . As in the $45^{\circ}$ angle plies, damage growth remained localized adjacent to the defect until a $0.911-\mathrm{MPa}$ (132-psi) pressure was reached. Substantial matrix degradations away from the defect also occurred as the pressure was gradually increased from 0.911 to $1.020 \mathrm{MPa}$ (132 to $148 \mathrm{psi}$ ). Fracture progression began at $1.765 \mathrm{MPa}$ (256 psi) by the extension of the axial slit. As the pressure increased, the circumferential slit also became extended. Structural fracture occurred at $1.90 \mathrm{MPa}(0.275 \mathrm{ksi})$, causing the cylindrical shell to burst.

Damage initiation in the $[90 / 0 / \pm 75]_{\mathrm{S}}$ shell began by matrix cracking adjacent to the defect as soon as the initial pressure of $0.172 \mathrm{MPa}$ ( $25 \mathrm{psi}$ ) was applied. Matrix failures at the circumferential slit tips were initiated by transverse tensile failures in ply 8 . As in the $45^{\circ}$ angle plies, damage growth remained localized adjacent to the defect. The ultimate structural fracture stage began as the pressure was increased to $0.621 \mathrm{MPa}(90 \mathrm{psi})$. Fracture progression was mainly by extension of the circumferential slit. Structural fracture occurred at $0.72 \mathrm{MPa}(0.104 \mathrm{ksi})$, causing the cylindrical shell to burst by a circumferential fracture. 
Figure 9 compares the overall damage progression histories for the three defective cylindrical shells. Damage initiation pressures and progression patterns are similar. However, burst pressures and structural fracture modes are strongly influenced by the laminate configuration. The $[90 / 0 / \pm 60]_{\mathrm{s}}$ laminate has the highest burst pressure, as is the case for the defect-free laminates. On the other hand, the $[90 / 0 / \pm 75]_{\mathrm{s}}$ defective laminate has the lowest damage initiation pressure, unlike the defect-free shells. The $[90 / 0 / \pm 45]_{\mathrm{s}}$ defective laminate has intermediate burst and damage progression pressures. An examination of structural fracture modes indicates that for the $[90 / 0 / \pm 45]_{\mathrm{s}}$ laminate, bursting occurs at the commencement of fracture propagation along the axial direction. For the $[90 / 0 / \pm 60]_{s}$ defective laminate, fracture also commences along the axial direction; however, a circumferential extension of the defect occurs at the same pressure level. On the other hand, for the $[90 / 0 / \pm 75]_{s}$ defective shell, fracture initiation and progression occur mainly in the circumferential direction. The circumferential fracture mode of the $[90 / 0 / \pm 75]_{S}$ laminate is considerably less damage tolerant. Table IV summarizes the burst pressures for the defect-free and defective shells. If damage tolerance is defined as the ratio of the defective to the defect-free burst pressures for each laminate, the $[90 / 0 / \pm 45]_{s}$ laminate would have a damage tolerance ratio of 33 percent; the $[90 / 0 / \pm 60]_{s}$ laminate, a ratio of 20 percent; and the [90/0/175] $]_{\mathrm{s}}$ laminate, a ratio of 9.2 percent for the assumed initial damage. However, if all burst pressures had been normalized with respect to the burst pressure of the defect-free $[90 / 0 / \pm 60]_{s}$ laminate, the damage tolerance ratio of the $[90 / 0 / \pm 45]_{\mathrm{s}}$ laminate would drop to 17 percent and that of the $[90 / 0 / \pm 75]_{\mathrm{s}}$ laminate would be reduced to 7.6 percent. These results indicate that the $[90 / 0 / \pm 60]_{\mathrm{s}}$ laminate has the best damage tolerance features in this application because of its well-balanced fiber reinforcement pattern.

Another perspective on damage progression characteristics may be obtained by quantifying the structural resistance to damage propagation. The global damage energy release rate (DERR) is defined as the rate of work done by external forces during structural degradation with respect to the damage produced. The DERR can be used to evaluate structural resistance to damage propagation at different stages of loading. Figure 10 shows the DERR as a function of the applied pressure for the defective $[90 / 0 / \pm 60]_{s}$ specimen. The DERR for damage initiation is relatively small, indicating a low resistance to damage initiation by matrix cracking. However, after the damage initiation stage, the DERR steadily increases, which indicates a greater structural resistance to damage propagation during a damage stabilization stage prior to global fracture. The maximum DERR level corresponds to the completion of the matrix cracking stage prior to the occurrence of ply fiber fractures.

Figure 11 shows the DERR levels for the defective $[90 / 0 / \pm 75]_{s}$ shell, for which the very low levels during the initial stages of damage progression indicate the lack of structural resistance to damage propagation and predict the sensitivity of damage progression to variations in the constituent material properties.

\section{CONCLUSIONS}

The computer code CODSTRAN (COmposite Durability STRuctural ANalysis) was used to evaluate the damage growth and propagation to fracture of cylindrical composite shells. The conclusions follow:

1. The CODSTRAN simulation demonstrates the progression of damage growth and subsequent propagation to fracture for defect-free and through-the-thickness defective composite shells subjected to internal pressure.

2. Through-the-thickness defects have a significant effect on the structural fracture pressure for internally pressurized thin shells. However, the damage initiation stage begins at low load levels for all simulated laminate configurations.

3. The damage stability after a major accident can be evaluated to serve as an index of the structural damage tolerance.

4. Computational simulation, with the use of established composite mechanics and finite element modules, can be utilized to predict the influence of existing defects, loading, constituent properties, and residual stresses on the safety and durability of composite structures.

5. The demonstrated procedure is flexible and applicable to all types of constituent materials, structural geometry, and loading. Hybrid composites and homogeneous materials as well as binary composites can be simulated.

6. The reduction in the ultimate pressure and the variation of the structural fracture mode are predictable with reference to the location and the size of the defect or the damage.

7. The procedure used herein demonstrated that fracture toughness parameters such as the structural fracture pressure and damage progression characteristics are identifiable for fiber composite structures with defects. 


\section{REFERENCES}

1. Gotsis, P.K.; Chamis, C.C.; and Minnetyan, L.: Defect Tolerance of Pressurized Fiber Composite Shell Structures. Proceedings of the 41 st International SAMPE Symposium and Exhibition, vol. 41, book 1, 1996, pp. $450-461$.

2. Gotsis, P.K.; Chamis, C.C.; and Minnetyan, L.: Effect of Combined Loads in the Durability of a Stiffened Adhesively Bonded Composite Structure. Proceedings of the 36th AIAA/ASME/ASCE /AHS/ASC Structures, Structural Dynamics, and Materials Conference, AIAA-95-1283-CP, pp. 1083-1092.

3. Minnetyan L.; and Gotsis, P.K.: Progressive Fracture in Adhesively Bonded Concentric Cylinders. Proceeding of the 40th International SAMPE Symposium and Exhibition, vol. 40, book 1, 1995, pp. 849-860.

4. Chamis, C.C.; Gotsis, P.K.; and Minnetyan, L.: Progressive Damage and Fracture of Adhesively Bonded Fiber Composite Pipe Joints. Energy Week Conference and Exhibition, Symposium on Composite Materials Design and Analysis, book V, legend V, 1996, pp. 401-408.

5. Chamis, C. C.; Gotsis, P. K.; and Minnetyan, L.: Damage Progression in Bolted Composite Structures. Proceedings of the USAF Structural Integrity Program Conference, 1995. Proceedings in publication.

6. Chamis, C.C.; Gotsis, P.K.; and Minnetyan, L.: Damage Tolerance of Composite Pressurized Shells. Proceedings of the 37th AIAA/ASME /ASCE/AHS/ASC Structures, Structural Dynamics, and Materials Conference, AIAA-96-1556-CP, part 4, 1996, pp. 2112-2121.

7. Gotsis, P.K.; Chamis, C.C.; and Minnetyan, L.: Progressive Fracture of Fiber Composite Builtup Structures. NASA TM-107231, 1996.

8. Minnetyan, L. et al.: Progressive Fracture of Composite Subjected to Iosipescu Shear Testing. Accepted for publication at the Proceedings for the 13th Symposium on Composite Material: Testing and Design, May 1996.

9. Murthy, P.L.N; Ginty, C.A.; and Sanfeliz, J.G.: Second Generation Integrated Composite Analyzer (ICAN) Computer Code. NASA TP-3290, 1993.

10. Nakazawa, S.: MHOST User's Manual, version 4.2, vol. 1, NASA CR-182235, 1989. 


\section{TABLE 1.-AS - 4 GRAPHITE FIBER PROPERTIES}

Number per end

Diameter, mm (in.)

10000

Density, $\mathrm{kg} / \mathrm{m}^{3}\left(\mathrm{lb} / \mathrm{in}^{3}{ }^{3}\right.$

$0.00762\left(0.300 \times 10^{-3}\right)$

Normal modulus, GPa (psi)

Longitudinal. $4.04 \times 10^{-7}(0.063)$

Transverse

$227\left(32.90 \times 10^{6}\right)$

Poisson's ratio

$v_{12}$

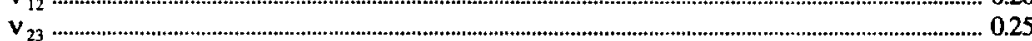

Shear modulus, GPa (psi)

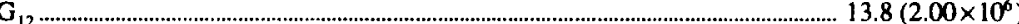

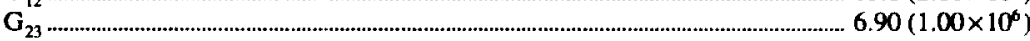

Thermal expansion coefficient, $1^{\circ} \mathrm{C}\left(/^{\circ} \mathrm{F}\right)$

Longitudinal

$1.0 \times 10^{-6}\left(-0.55 \times 10^{-6}\right)$

Transverse

$1.0 \times 10^{-6}\left(-0.56 \times 10^{-6}\right)$

Heat conductivity, $\mathrm{J}-\mathrm{m} / \mathrm{hr} / \mathrm{m}^{2} /{ }^{\circ} \mathrm{C}\left(\mathrm{BTU}-\mathrm{in} . / \mathrm{hr} / \mathrm{in} .{ }^{2} /{ }^{\circ} \mathrm{F}\right)$

Longitudinal.

$43.4(580)$

Transverse

$4.34(58)$

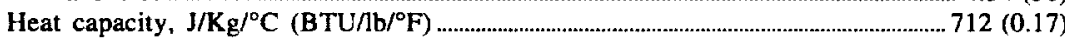

Strength, MPa (ksi)

Tensile. $3723(540)$

Compressive $3351(486)$

TABLE II.-HMHS EPOXY MATRIX PROPERTIES

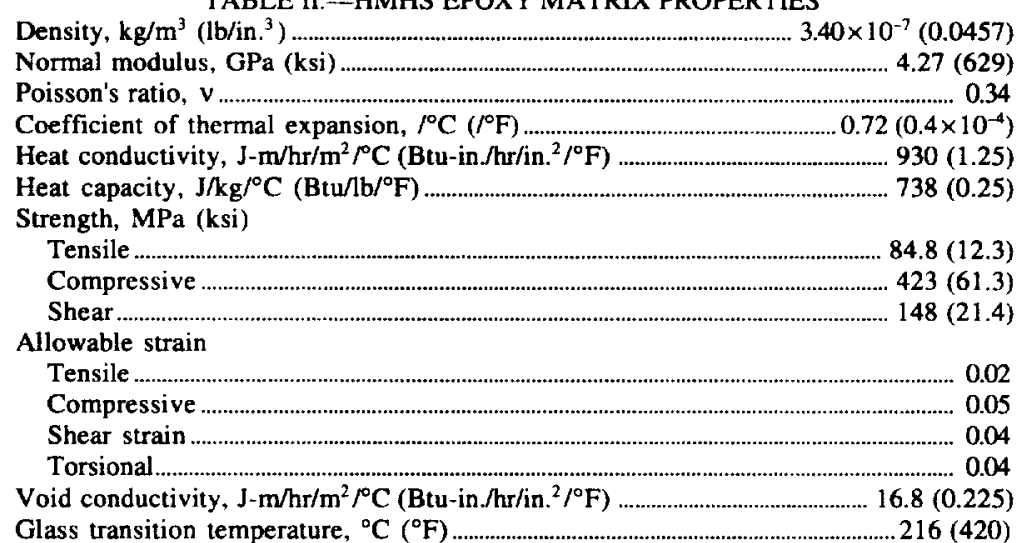

TABLE III-PLY STRENGTH OF AS-4/HMHS [Fiber direction, parallel to ply 1 material axis: tension, $T$; compression, $C$; material axes of ply, 1 to 3 .]

\begin{tabular}{|c|c|c|}
\hline \multirow{2}{*}{ Ply stress component } & \multicolumn{2}{|c|}{ Strength } \\
\cline { 2 - 3 } & $\mathrm{MPa}$ & $\mathrm{ksi}$ \\
\hline$S_{\ell 11 \mathrm{~T}}$ & 1930.30 & 280 \\
$S_{\ell 11 \mathrm{C}}$ & 1475.85 & 210 \\
$S_{\ell 22 \mathrm{~T}}$ & 91.38 & 13 \\
$S_{\ell 2 C}$ & 228.27 & 33 \\
$S_{\ell 12}$ & 65.57 & 9.5 \\
$S_{\ell 23}$ & 59.98 & 8.7 \\
\hline
\end{tabular}

TABLE IV - BURST PRESSURES

\begin{tabular}{|c|c|c|c|c|}
\hline \multirow{2}{*}{ Laminate } & \multicolumn{4}{|c|}{ Shell structure } \\
\cline { 2 - 5 } & \multicolumn{2}{|c|}{ Defect free } & \multicolumn{2}{|c|}{ Defective } \\
\cline { 2 - 5 } & \multicolumn{4}{|c|}{ Burst pressure } \\
\cline { 2 - 5 } & $\mathrm{MPa}$ & $\mathrm{ksi}$ & $\mathrm{MPa}$ & $\mathrm{ksi}$ \\
\hline$[90 / 0 / \pm 45]_{\mathrm{b}}$ & 4.8 & 0.696 & 1.58 & 0.230 \\
{$[90 / 0 / \pm 60]_{\mathrm{b}}$} & 9.42 & 1.366 & 1.90 & .2755 \\
{$[90 / 0 / \pm 75]_{\mathrm{s}}$} & 7.83 & 1.135 & .72 & .104 \\
\hline
\end{tabular}




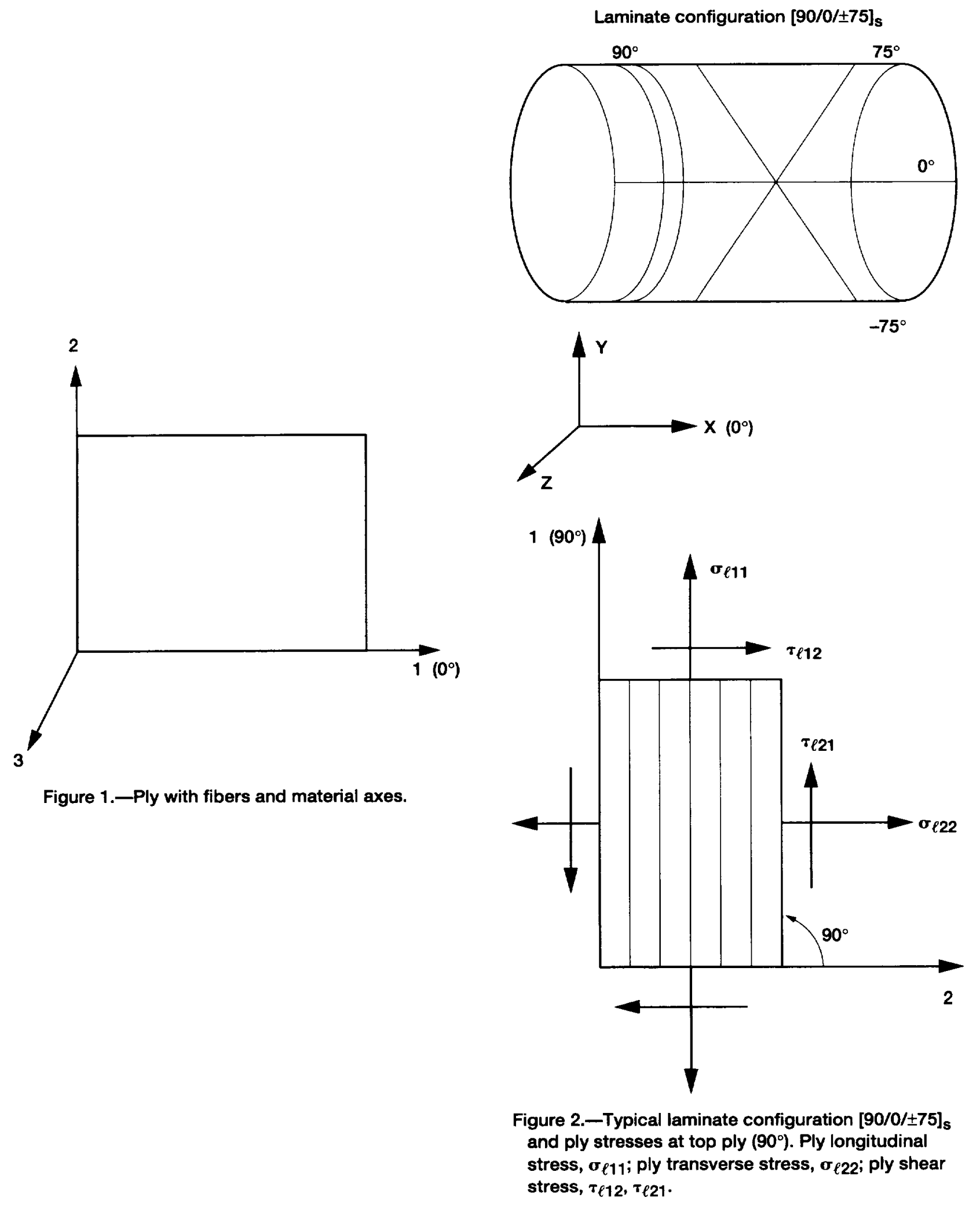




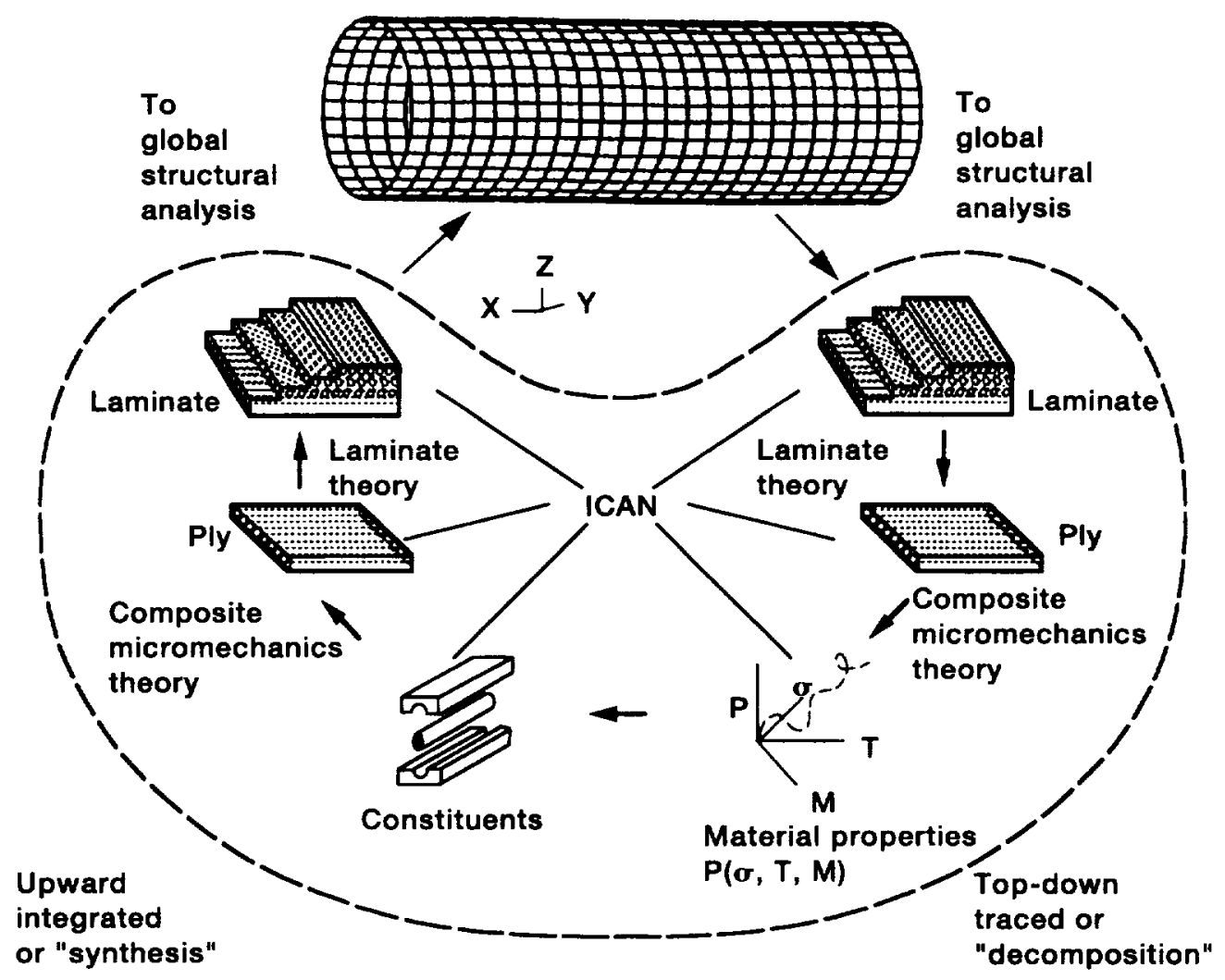

Figure 3.-CODSTRAN progressive fracture simulation cycle.

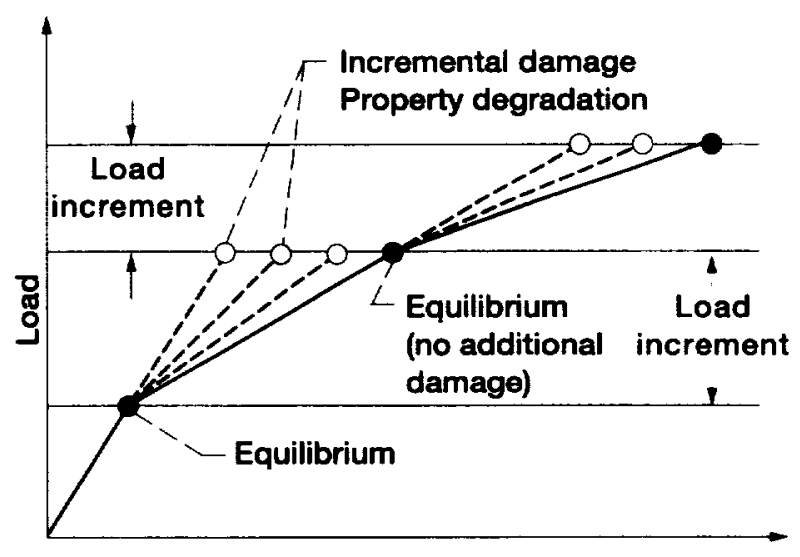

Displacement

Figure 4.-CODSTRAN load incrementation. 


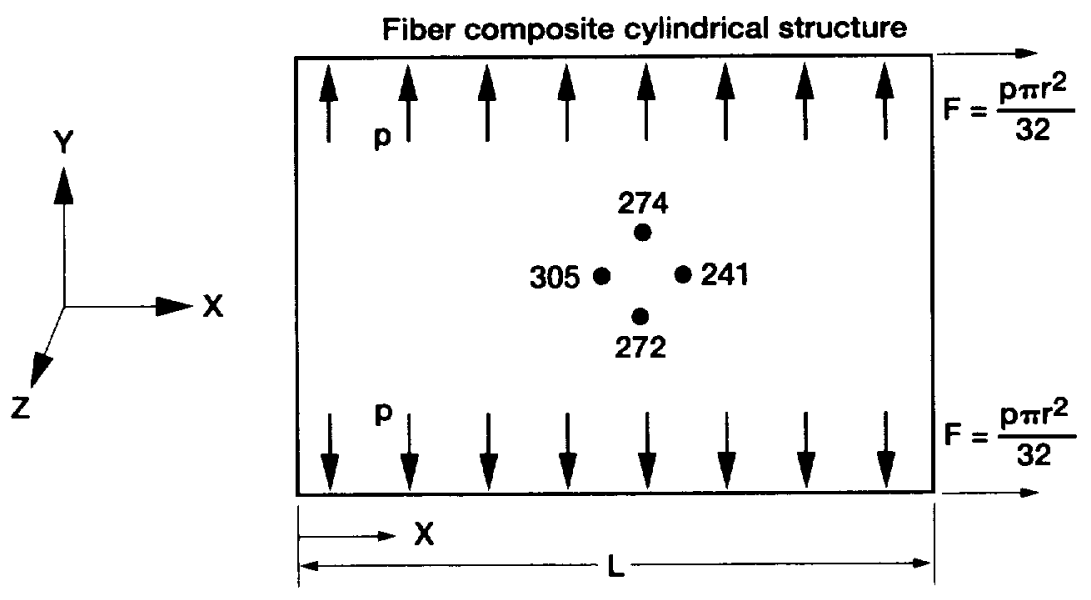

Boundary conditions

AT $X=0, U_{X}=U_{y}=U_{z}=0$

AT $X=L, U_{y}=U_{z}=0$

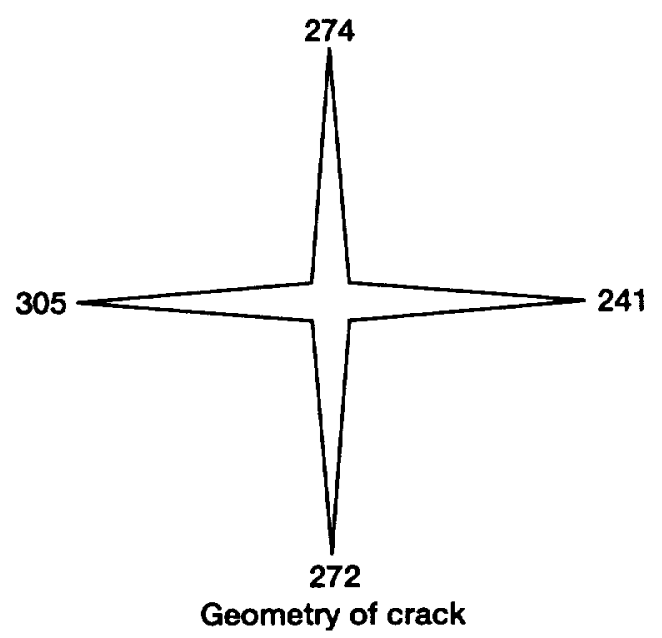

Figure 5.-Applied loads and boundary conditions of thin shell structures. Cylinder length, $L, 762 \mathrm{~mm}$ ( 30 in.); inner radius, $r, 152.4 \mathrm{~mm}$ (6 in.); laminate thickness, $t, 1.088 \mathrm{~mm}$ (0.0428 in.); graphite/epoxy fiber volume fraction, 60 percent. 


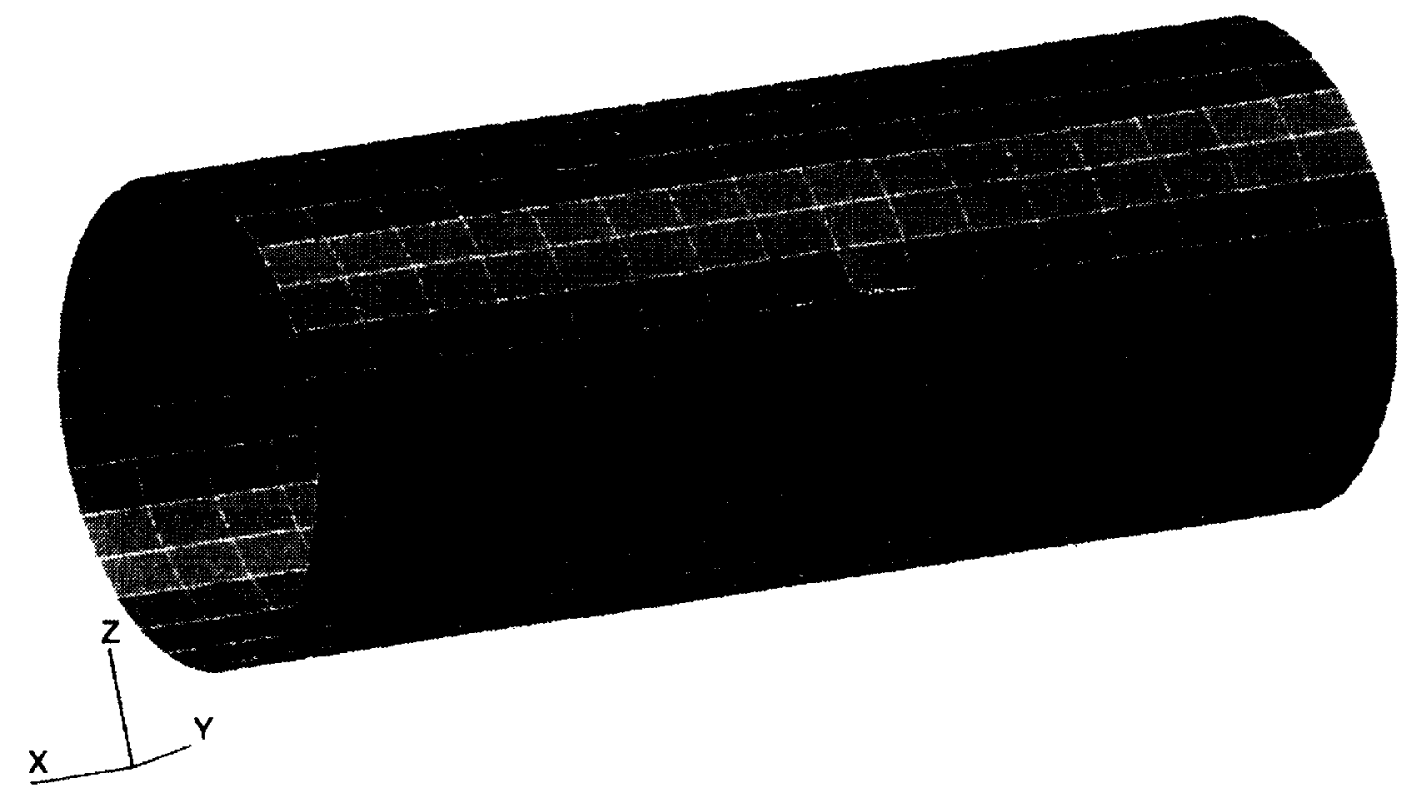

Figure 6.-Finite element mesh of graphite/epoxy composite thin shell.

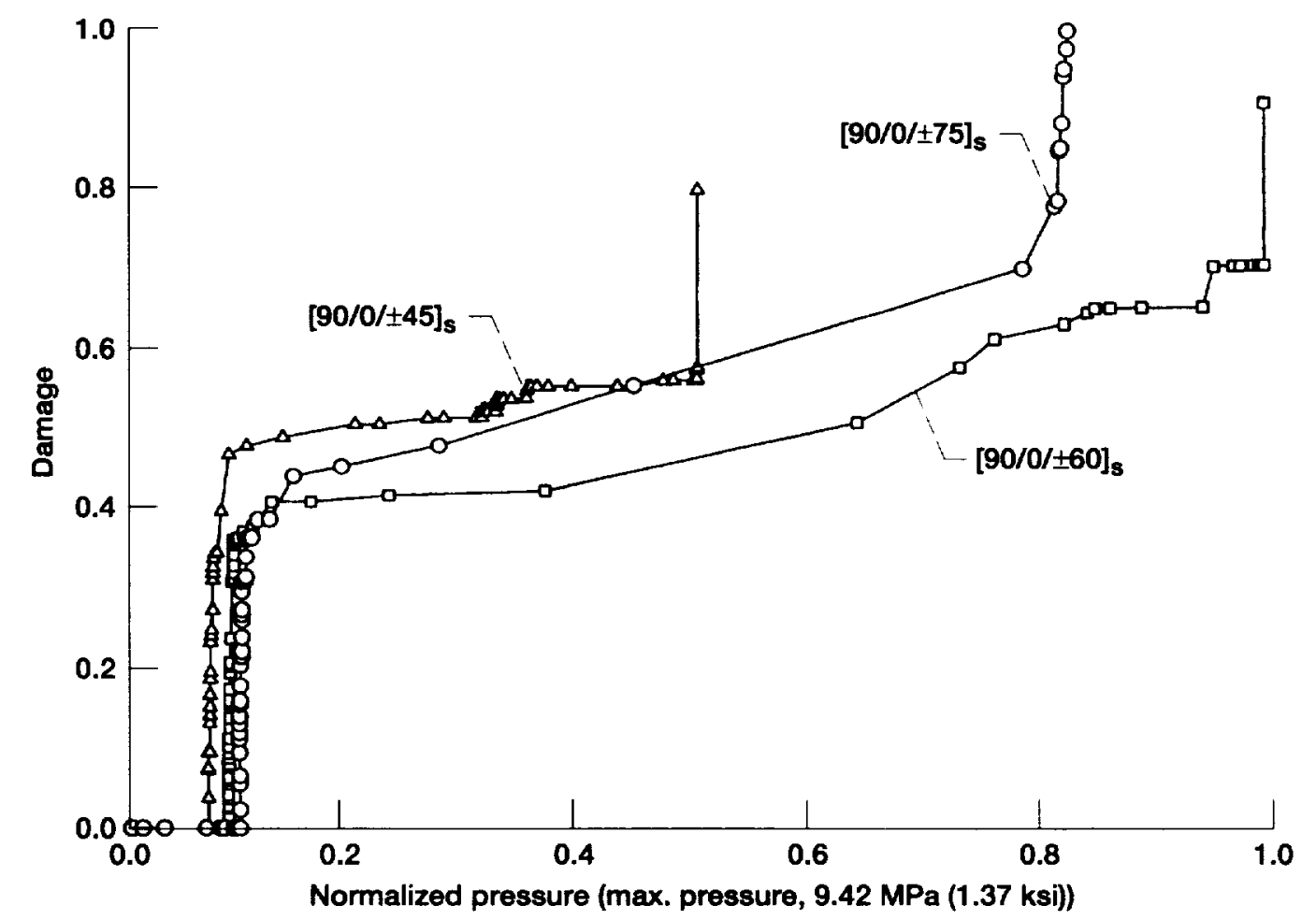

Figure 7.-Damage progression in defect-free graphite/epoxy thin cylindrical shells $[90 / 0 / \pm \theta]_{5}$. 


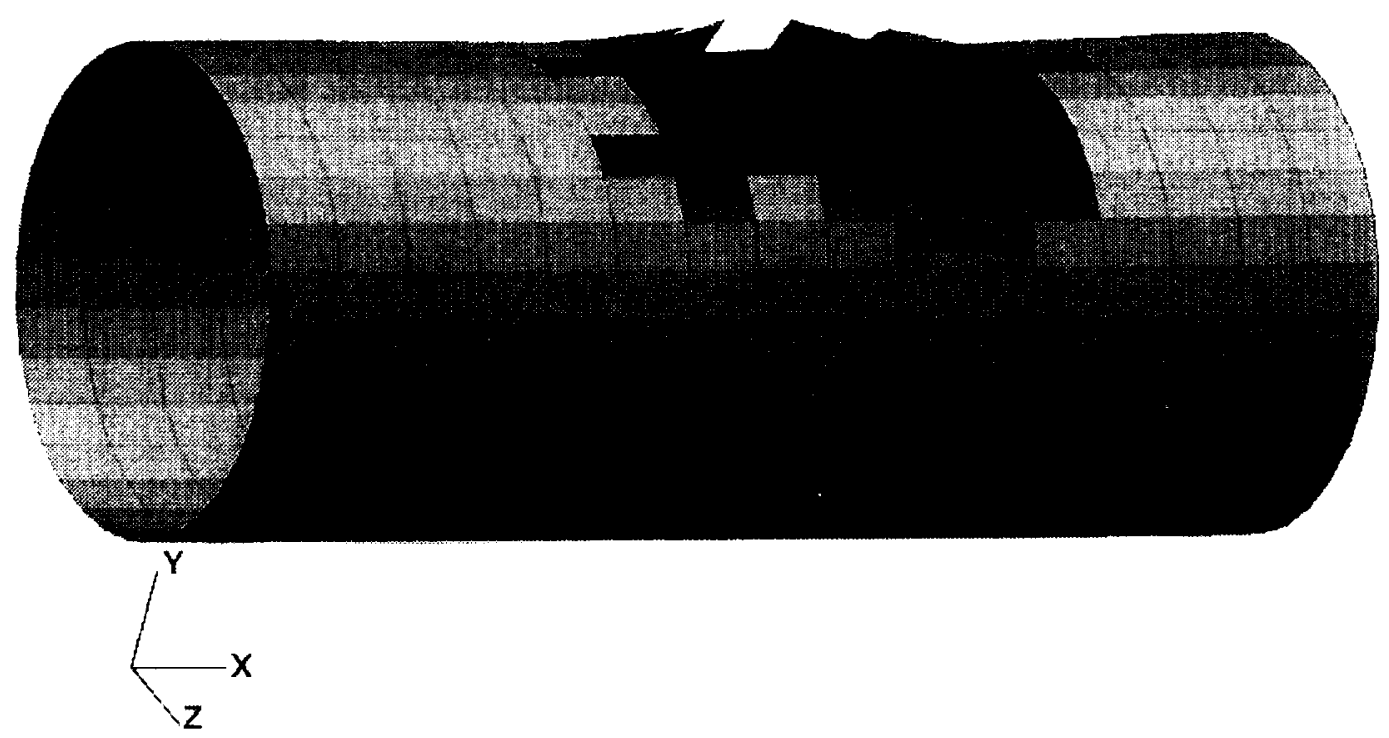

Figure 8.-Burst of defective shell $[90 / 0 / \pm 45]_{s}$.

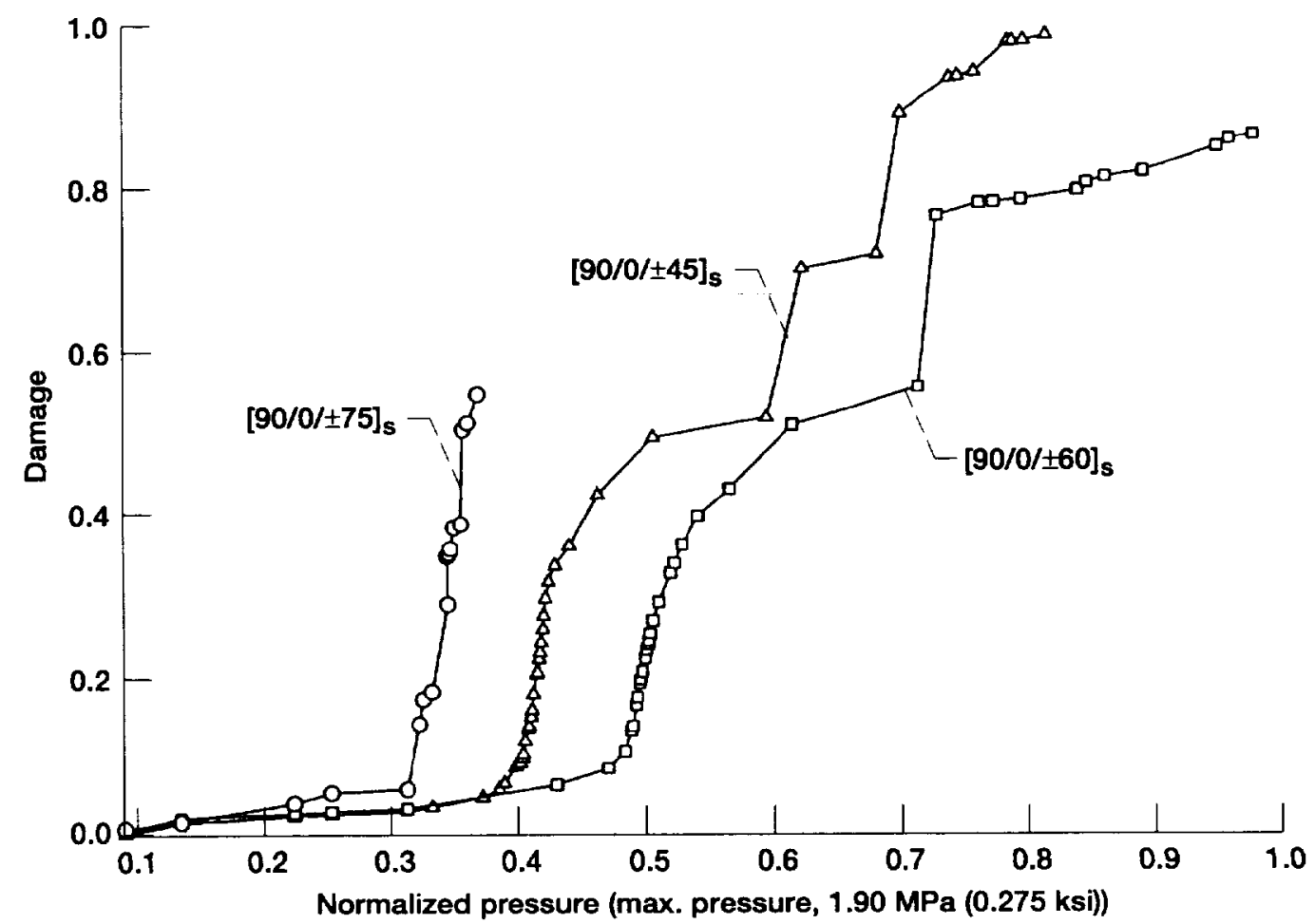

Figure 9.-Damage progression in defective graphite/epoxy thin cylindrical shells $[90 / 0 / \pm \theta]_{s}$. 


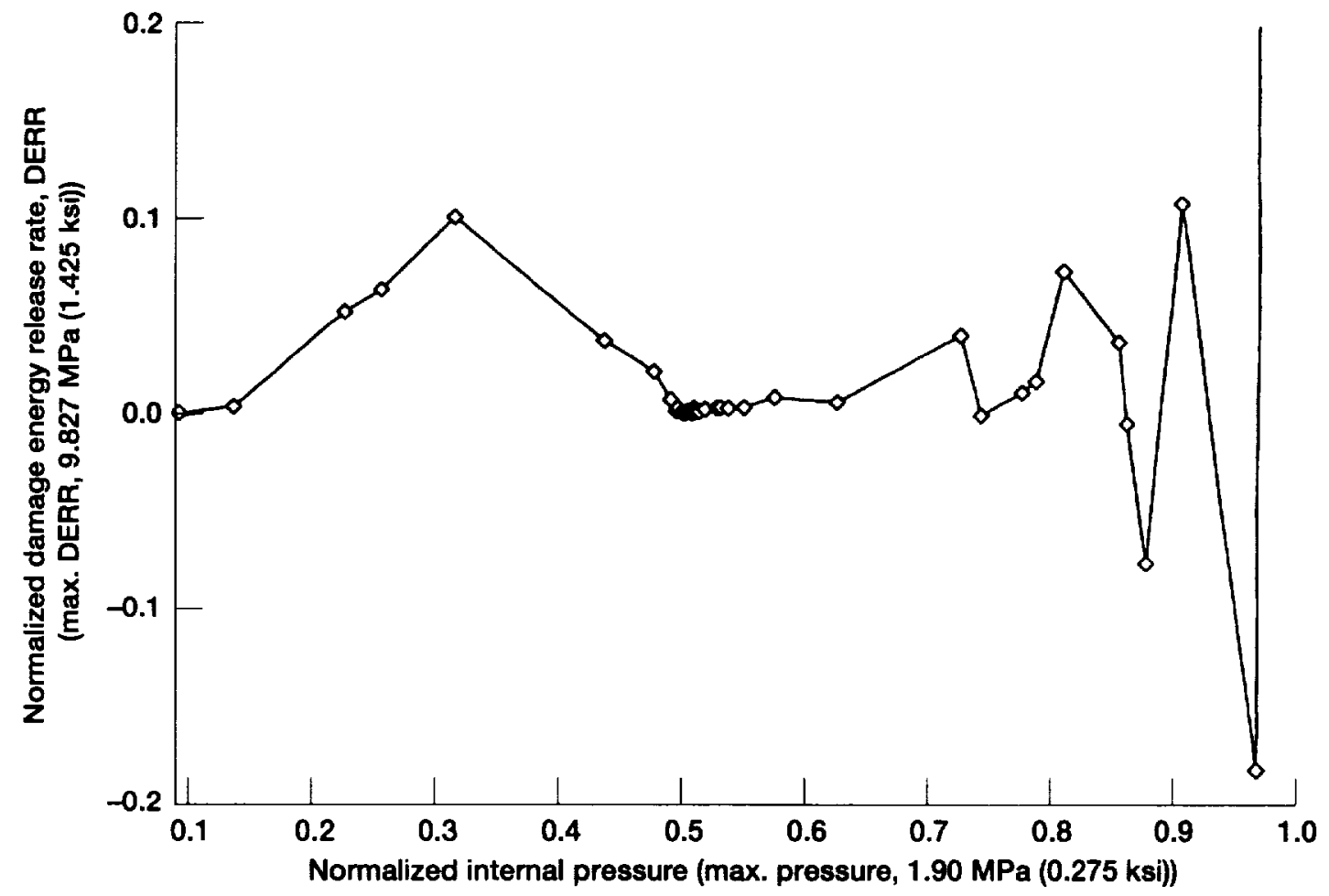

Figure 10.-Damage energy release rate (DERR) levels for defective thin cylindrical shells $[90 / 0 / \pm 60]_{s}$.

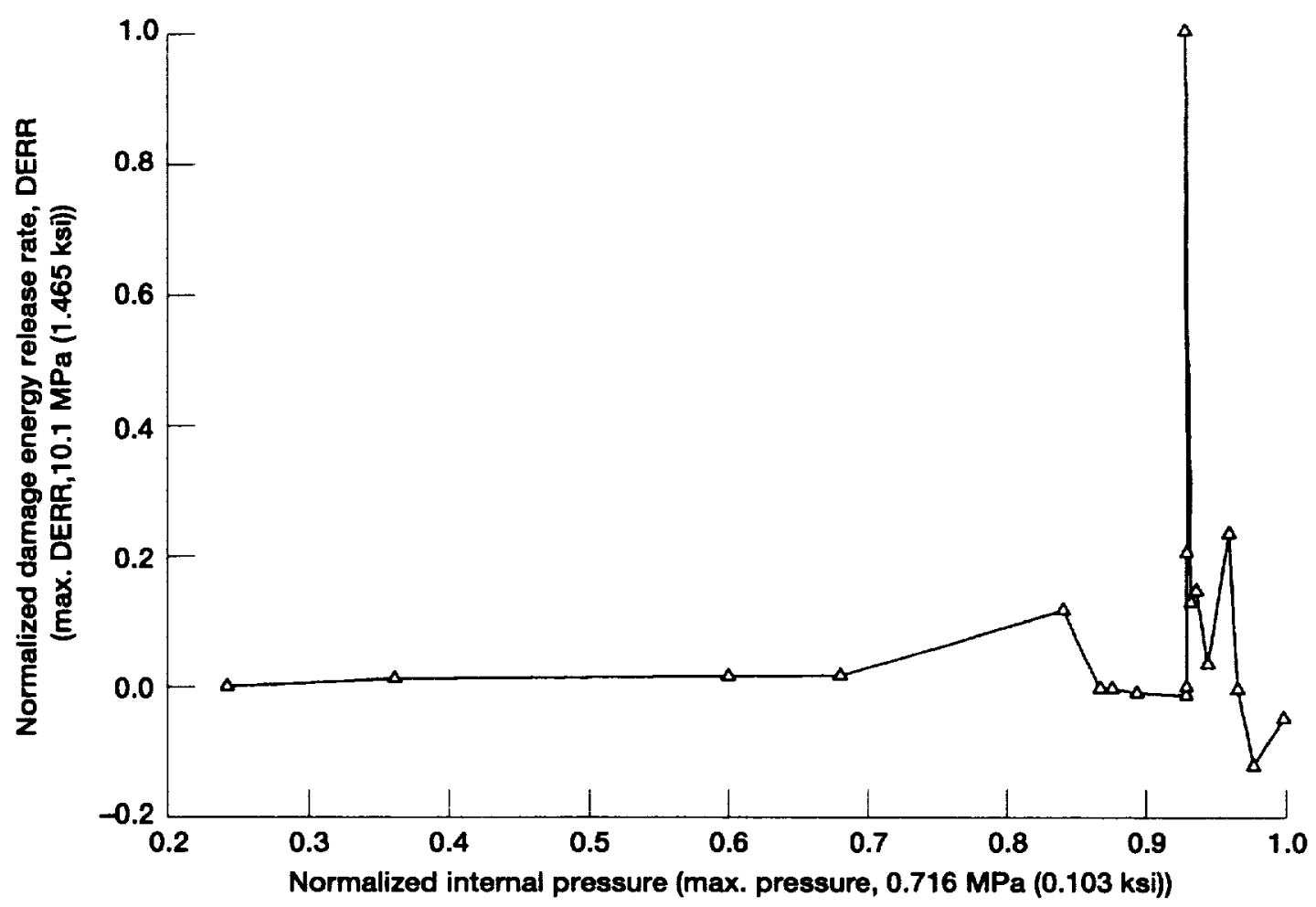

Figure 11.-Damage energy release rate (DERR) levels for defective thin cylindrical shells $[90 / 0 / \pm 75]_{s}$. 

Public reporting burden for this collection of information is estimated to average 1 hour per response, inciuding the time for reviewing instructions, searching existing data sources, gathering and maintaining the date needed, and completing and reviewing the collection of information. Send comments regarding this burden estimate or any other aspect of this Davis Highway, Suite 1204, Artington, VA 22202-4302, and to the Office of Management and Budget, Paperwork Feduction Project (0704-0188). Washington, DC 20503.

\begin{tabular}{|l|c|c|}
\hline 1. AGENCY USE ONLY (Leave blank) & $\begin{array}{c}\text { 2. REPORT DATE } \\
\text { September } 1996\end{array}$ & $\begin{array}{r}\text { 3. REPORT TYPE AND DATES COVERED } \\
\text { Technical Memorandum }\end{array}$ \\
\hline
\end{tabular}

\section{TITLE AND SUBTITLE}

Progressive Fracture of Fiber Composite Thin Shell Structures Under Internal Pressure and Axial Loads

6. AUTHOR(S)

Pascal K. Gotsis, Christos C. Chamis, and Levon Minnetyan
5. FUNDING NUMBERS

WU-505-63-5B

\section{PERFORMING ORGANIZATION NAME(S) AND ADDRESS(ES)}

National Aeronautics and Space Administration Lewis Research Center

Cleveland, Ohio 44135-3191

9. SPONSORINGMONITORING AGENCY NAME(S) AND ADDRESS(ES)

National Aeronautics and Space Administration

Washington, DC 20546-0001
8. PERForming organization REPORT NUMBER

E-10277

10. SPONSORING/MONITORING AGENCY REPORT NUMBER

NASA TM-107234

11. SUPPLEMENTARY NOTES

Pascal K. Gotsis and Christos C. Chamis, NASA Lewis Research Center; Levon Minnetyan, Clarkson University, Potsdam, New York 13699-5710. Responsible person, Pascal K. Gotsis, organization code 5210, (216) 433-3331.

12a. DISTRIBUTIONVAVAILABILITY STATEMENT

Unclassified - Unlimited

Subject Category 39

This publication is available from the NASA Center for AeroSpace Information, (301) $621-0390$.

\section{ABSTRACT (Maximum 200 words)}

Graphite/epoxy composite thin shell structures were simulated to investigate damage and fracture progression due to internal pressure and axial loading. Defective and defect-free structures (thin cylinders) were examined. The three different laminates examined had fiber orientations of $[90 / 0 / \pm \theta]_{\mathrm{s}}$, where $\theta$ is $45^{\circ}, 60^{\circ}$, and $75^{\circ}$. CODSTRAN, an integrated computer code that scales up constituent level properties to the structural level and accounts for all possible failure modes, was used to simulate composite degradation under loading. Damage initiation, growth, accumulation, and propagation to fracture were included in the simulation. Burst pressures for defective and defect-free shells were compared to evaluate damage tolerance. The results showed that damage initiation began with matrix failure whereas damage and/or fracture progression occurred as a result of additional matrix failure and fiber fracture. In both thin cylinder cases examined (defective and defect-free), the optimum layup configuration was $[90 / 0 / \pm 60]_{\mathrm{s}}$ because it had the best damage tolerance with respect to the burst pressure.

\section{SUB.JECT TERMS}

Fiber composite structures; Thin cylindrical shells; Graphite/epoxy; Residual stresses; Finite element analysis; Damage initiation and damage propagation; Burst pressure.

\begin{tabular}{|c|c|}
\hline 17. SECURITY CLASSIFICATION & 18. SECURITY CLASSIFICATION \\
OF REPORT & OF THIS PAGE \\
Unclassified & Unclassified
\end{tabular}

NSN 7540-01-280-5500

\section{SECUAITY CLASSIFICATION OF ABSTRACT} Unclassified
15. NUMBER OF PAGES 17

16. PRICE CODE

$\mathrm{A} 03$

20. LIMITATION OF ABSTRACT 